\title{
Conexões de conhecimento e posturas tecnológicas das firmas: evidências da aglomeração industrial de petróleo e gás da Bacia de Campos
}

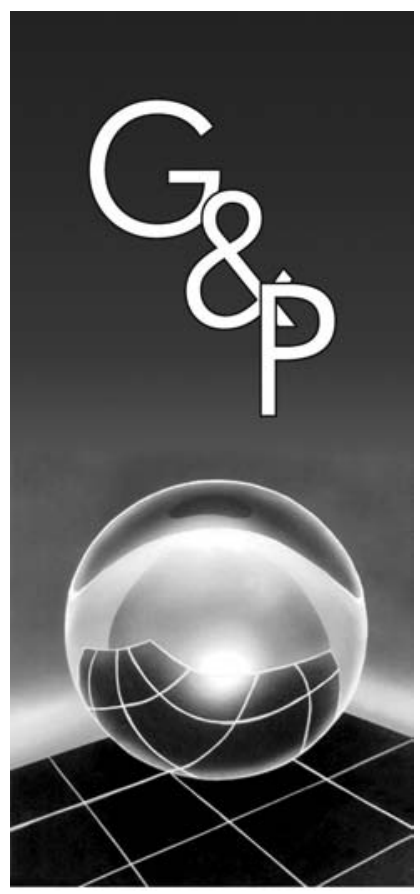

\author{
Bruno dos Santos Silvestre \\ Paulo Roberto Tavares Dalcol
}

\section{Resumo}

O presente trabalho analisa os resultados de uma pesquisa empírica que envolveu dez firmas pertencentes à aglomeração industrial de petróleo e gás da região produtora da Bacia de Campos (RJ). As empresas envolvidas neste estudo atuam em áreas de intenso dinamismo tecnológico e fornecem produtos e serviços de alta complexidade tecnológica para as operadoras de campos de petróleo e gás atuantes naquela localidade. Dois grupos de firmas receberam atenção especial: os fornecedores de equipamentos de poço (árvore de natal molhada) e os fornecedores de serviços de poço (tecnologia de poço). Para isso, elaborou-se um modelo híbrido de análise de aglomerações que utiliza elementos da abordagem de clusters e de sistemas de inovação (setoriais e tecnológicos). O propósito do trabalho consiste em determinar o processo de formação e a caracterização da aglomeração, e entender, sob o foco do sistema de conhecimento e das posturas tecnológicas das firmas, como são implementadas e qual a origem das mudanças tecnológicas aplicadas na Bacia de Campos, nos anos recentes. Busca-se verificar, como objetivo secundário, se a aglomeração geográfica favorece a inovação das firmas ali localizadas. Os resultados mostram evidências da existência de grupo de firmas, no qual a proximidade geográfica exerce influência positiva para as atividades inovadoras.

Palavras-chave: Aglomeração industrial. Petróleo e gás. Sistemas de inovação. Sistema de conhecimento. Mudanças tecnológicas.

\section{Introdução}

Nas últimas décadas, a busca pelo petróleo gerou avanços tecnológicos nas atividades de exploração, desenvolvimento e produção. Situações como a exploração de petróleo e gás natural em alto mar, fazem parte, atualmente, da realidade para as firmas da indústria. Para que todo esse avanço seja possível, as operadoras e fornecedores de equipamentos e serviços offshore têm aplicado esforços substanciais em pesquisa e desenvolvimento (P\&D) para viabilizar a extração de petróleo e gás natural em águas ultraprofundas, e diminuir os custos operacionais das atividades de E\&P (Exploração e Produção).

Pode-se destacar algumas perguntas básicas que surgem na etapa de E\&P e que consistem grandes desafios tecnológicos da indústria. São elas: quais equipamentos devem ser utilizados em um determinado campo/poço petrolífero? Quais sistemas e estruturas de produção seriam necessários? Existe base técnica/tecnológica para execução de tal projeto de E\&P? Se existe base técnica/ tecnológica para execução do projeto, este é viável econo- micamente? Se não existe base técnica/tecnológica para a execução do projeto, existe a possibilidade de desenvolvimento de sistemas que o tornem viável?

Para responder a essas perguntas, surge a necessidade de aplicação de recursos em pesquisa e desenvolvimento (P\&D), desenvolvimento de novos produtos, processos e conceitos para a transposição das barreiras técnicas/ tecnológicas que as novas descobertas impõem. Portanto, a etapa de E\&P de petróleo e gás natural tem sido alvo de mudanças tecnológicas e do dinamismo, que são o foco de interesse deste trabalho. A complexidade e a base multidisciplinar exigida para a resolução de problemas e para o desenvolvimento de novas estruturas e sistemas de produção, em alguns casos, fazem com que as empresas se organizem de forma aglomerada (próximas geograficamente) para a execução de tais tarefas. Essa estrutura aglomerada forma uma rede de fornecimento, em que o papel de 'empresa âncora', na aglomeração industrial da região produtora da Bacia de Campos (BC), é exer- 
cido pela Petrobras. Como a indústria em questão pode ser classificada como intensiva em recursos naturais (petróleo e gás) e por questões relacionadas à logística, essa concentração de firmas se organiza, na maioria das vezes, nas proximidades das jazidas, formando o que é conhecido como 'província petrolífera'.

A província petrolífera da Bacia de Campos (BC) consiste em uma aglomeração geográfica de cerca de 1.500 firmas que atuam no segmento de exploração e produção $(\mathrm{E} \& \mathrm{P})$ de petróleo e gás offshore. Do total, cerca de 400 firmas atuam diretamente em atividades offshore. As demais firmas atuam em atividades de apoio aos fornecedores maiores e às operadoras de campos de petróleo e gás natural, localizadas na $\mathrm{BC}$.

Entretanto, as firmas atuantes como fornecedoras de bens e serviços de alta complexidade tecnológica, em áreas de alto dinamismo tecnológico, possuem fortes conexões externas ao aglomerado, fortes características sistêmicas e tendências de internacionalização. Além disso, utilizam equipamentos que, muitas vezes, trazem elementos localizados na fronteira tecnológica, ressaltando assim, a importância do conhecimento, das mudanças tecnológicas, das inovações e do dinamismo de seus atores (elementos aqui conceituados, segundo abordagem definida em BELL; ALBU, 1999).

Essas características fazem com que os relacionamentos e as parcerias entre as firmas sejam de interesse para elas, em virtude da necessidade de absorver conhecimento e tecnologia das outras organizações, e pelo fato das províncias petrolíferas seguirem um ciclo natural de nascimento, crescimento, maturação e declínio. Com essa estrutura de evolução, uma relação de sucesso entre firmas, em uma determinada província petrolífera, pode representar a continuação dessa parceria em outras províncias ao redor do mundo, abrindo assim, novos mercados e oportunidades.

Com base nas características supracitadas, o foco desta análise está voltado para os aspectos tecnológicos desta aglomeração industrial, bem como para o estabelecimento de sua caracterização atual. O objetivo geral deste trabalho é investigar a aglomeração industrial de petróleo e gás da região produtora da Bacia de Campos, procurando determinar o processo de formação e a caracterização da aglomeração, e entender as mudanças tecnológicas ocorridas em anos recentes. $\mathrm{O}$ trabalho consiste em um estudo exploratório, cuja estrutura metodológica envolveu a definição de um modelo conceitual híbrido, que serviu como referencial de análise, e um estudo de campo englobando dez empresas selecionadas. A utilização de elementos de duas abordagens distintas (modelo híbrido) - clusters e sistemas de inovação - ainda não encontra paralelo na literatura da área.

\section{Revisão bibliográfica}

A multiplicidade de nomenclaturas e expressões presentes na literatura referente às aglomerações de firmas (cluster, milieu, filières, redes de cooperação, distritos industriais, consórcios industriais, cadeia de suprimentos, arranjos, sistemas locais, entre outras) torna a definição da base conceitual dos trabalhos nesta área um pouco nebulosa.

Isso decorre do fato desta área de estudo apresentar desenvolvimento recente e estar permeada de certo dinamismo. Muitos autores nacionais propõem suas próprias nomenclaturas e tipologias (CASAROTTO FILHO; PIRES, 1999; AMATO NETO, 2000; CASSIOLATO; SZAPIRO, 2002), o que amplia sobremaneira as metodologias de análise nesse campo.

A dificuldade da comunidade que atua nesta área em adotar uma ou algumas poucas nomenclaturas básicas faz com que haja perda considerável de sinergia entre os trabalhos, obstruindo o estabelecimento de abordagens teóricas e de metodologias de análise que sejam utilizadas de forma mais padronizada, por diversos pesquisadores e em diferentes contextos.

Por esses motivos, buscou-se denominar a aglomeração industrial estudada apenas de 'aglomeração' ou 'aglomerado', e que representa uma concentração geográfica de firmas que atuam em uma mesma indústria.

Nesta revisão bibliográfica, busca-se destacar as contribuições seminais de cada uma das abordagens utilizadas no estudo, sem, no entanto, esgotar todas as nomenclaturas e estudos disponíveis na literatura da área. É nesse aspecto inclusive, que reside a diferenciação deste trabalho em relação a vários outros, nos quais pouco se discute além de tipologias e nomenclaturas.

\subsection{Arranjos interfirmas}

Do trabalho precursor de Alfred Marshall (1920) até os dias de hoje, muitos estudos referentes às externalidades dos aglomerados têm sido produzidos no mundo todo. Pesquisadores e homens públicos têm classificado os aglomerados por diferentes nomenclaturas, ao longo desse tempo, tais como: distritos industriais, milieus, clusters, redes, arranjos, sistemas e outras.

Seguindo essa linha de raciocínio, Porter (1990; 1998), em seu famoso livro "A Vantagem Competitiva das Nações", popularizou o conceito de cluster industrial nos círculos industrial, acadêmico e político. Daí em diante, o conceito de cluster tornou-se 'palavra mágica' nesses círculos, e um grande número de adeptos começou a trabalhar com o referido conceito. Nesse contexto, estudos teóricos e empíricos sob a abordagem de cluster industrial são fáceis de serem encontrados. Para o autor, clusters são concentrações geográficas de firmas e instituições interconectadas em um campo particular. 
O conceito de cluster está, portanto, relacionado a uma concentração geográfica de firmas em um ou mais setores correlatos ou indústrias complementares (não necessariamente na mesma indústria ou setor), e espacialmente concentradas. Pesquisadores trabalhando em estudos relacionados a cluster, geralmente dão especial atenção à proximidade territorial, com a qual as firmas operam. Estes aglomerados situam-se no mesmo espaço geográfico, que pode estar delimitado por uma única cidade, uma região, um estado ou mesmo um país (ALBU, 1997; BASANT, 2002).

A abordagem de clusters é geralmente utilizada em um contexto que apresenta algumas características específicas: estrutura do setor focada em atividades de transformação (manufatura e serviços), aspectos industriais e conexões baseadas em fluxos de bens e serviços. Alguns exemplos são, entre outros, os setores de calçados, cerâmica de revestimento, tijolos, móveis, vinho, etc (SCHMITZ; NADVI, 1999; BELL; ALBU, 1999; GIULIANI, 2004). Por esta razão, pode-se afirmar que na análise de clusters, o setor econômico em que este está inserido é relevante, ou seja, deve ser considerado obrigatoriamente na análise. Nesse caso, se o setor deve ser levado em conta, a diferença entre os setores pode representar uma importante característica a ser ressaltada em análises e, principalmente, comparações entre clusters industriais (PAVITT, 1984). No entanto, vários estudos que utilizam a abordagem de clusters se focam na estrutura de conexões, mas com pouca ênfase nas conexões de conhecimento, nas mudanças tecnológicas e na inovação (GIULIANI, 2004; MALMBERG, 2003; MALMBERG; MASKELL, 2002). Nessa situação, em aglomerações industriais de setores tecnologicamente dinâmicos, a abordagem de cluster pode apresentar limitações.

Com base nesse argumento, deve ser considerado o elemento global (sem fronteiras geográficas definidas) e sistêmico da abordagem de sistemas de inovação. $\mathrm{O}$ termo 'sistêmico' introduz a diversidade de atores e a complexidade das relações e conexões como duas das principais características. 'Diversidade de atores', no sentido de analisar cuidadosamente não somente as firmas, mas também o papel das diversas organizações que contribuem para o desenvolvimento das atividades do aglomerado (instituições de apoio), tais como: universidades, institutos de pesquisa, organizações reguladoras, organizações públicas, organizações de financiamento, etc. 'Complexidade das relações e conexões', no sentido de dar ênfase às relações e conexões intra-aglomerado (entre firmas ou entre firmas e organizações de apoio dentro do próprio aglomerado) e extra-aglomerado (entre firmas ou organizações situadas dentro do aglomerado com firmas ou organizações situadas fora do aglomerado - cross-bounderies) sem privilegiar as primeiras, enfoque encontrado em muitos estudos que utilizam a abordagem de clusters (BATISTA; SWANN, 1998; BEAUDRY; BRESCHI, 2003; MALMBERG, 2003).

Conexões de conhecimento são definidas como relacionamentos entre agentes (firmas e outras organizações) que, diferentemente das conexões de produção, que são compostas de produtos e serviços e acompanham a direção do fluxo da cadeia produtiva, apresentam fluxos compostos de conhecimento e estão relacionadas a atividades de geração, transmissão e absorção desse conhecimento. Essas conexões de conhecimento podem permitir às firmas construir suas redes de relacionamentos estáveis baseadas em confiança, facilitando o acesso a novos mercados, tanto nacionais quanto internacionais (BELL; ALBU, 1999). Essa estratégia pode ser fundamental em setores como o de E\&P de petróleo e gás, no qual a tendência à internacionalização parece ser primordial para a sustentabilidade das firmas a longo prazo.

As conexões intra-aglomerado podem ser importantes para o estabelecimento de relacionamentos com outras firmas e organizações, proporcionando às firmas a construção de redes de absorção de conhecimento e parcerias mais estreitas, sob as quais muitas das novas mudanças tecnológicas implementadas no aglomerado podem surgir. Conexões entre organizações próximas geograficamente podem apresentar melhores resultados em virtude da facilidade de contato direto, discussão de novas técnicas, surgimento de relacionamentos informais e extrafirma. Essa questão ganha importância em províncias de petróleo e gás, onde as características e condições naturais são bastante peculiares (i.e. os problemas são melhor discutidos e solucionados, entre firmas que vivenciam aquela realidade).

No entanto, as conexões extra-aglomerado podem exercer também um papel importante para que a aglomeração possa se 'renovar' e se 'revitalizar', no que diz respeito à base de conhecimento, trocando conhecimento com o ambiente externo e evitando ficar 'presa' tecnologicamente a fluxos internos de conhecimento. Os efeitos da limitação de conexões externas ao aglomerado (estrutura que pode ser classificada como um sistema fechado) poderiam levar à perda da direção das mudanças tecnológicas e inovações realizadas no ambiente externo, podendo gerar um descompasso com as tendências e sua decadência definitiva a longo prazo (BELL; ALBU, 1999).

Portanto, as conexões de conhecimento, tanto internas quanto externas, bem estabelecidas e sedimentadas, podem contribuir para o processo de aprendizagem das firmas, permitindo que estas adquiram capacitações tecnológicas para enfrentar os desafios impostos pelo mercado e realizar mudanças tecnológicas e inovações, as quais são, atualmente, alguns dos principais recursos para a sustentabilidade das firmas no longo prazo (FIGUEIREDO, 2003; BELL; ALBU, 1999). 


\subsection{Abordagem de inovação}

A abordagem de Sistemas de Inovação (SI) está relacionada, conforme o termo sugere, a 'sistemas' - que remete à idéia de complexidade das conexões e diversidade de atores, como mencionado anteriormente - e à 'inovação' - que remete à idéia de dinamismo e mudanças tecnológicas. $\mathrm{O}$ dinamismo está relacionado às mudanças tecnológicas, por meio das quais as firmas se adaptam e se modificam constantemente, buscando a sustentabilidade a longo prazo. (EDQUIST, 1997; NELSON; NELSON, 2002; CARLSSON et al., 2002; FREEMAN, 1995).

A abordagem dos Sistemas Setoriais de Inovação (SSI) complementa a abordagem dos sistemas de inovação (local, regional e nacional) e dos sistemas tecnológicos. Esta abordagem foca a inovação em um setor específico, ou seja, concentrado dentro dos limites setoriais. A abordagem de SSI usa uma visão multidimensional, integrada e dinâmica de setores, a fim de analisar a inovação, e tem origem no conceito de setor, tradicionalmente utilizado na economia industrial, porque este considera outros agentes que devem ser analisados além das firmas. Esta abordagem dispensa maior ênfase ao conhecimento, à aprendizagem e aos limites setoriais, foca as interações de não-mercado, assim como as interações de mercado, e presta bastante atenção às instituições (MALERBA, 2004).

A abordagem de Sistemas Tecnológicos de Inovação (STI) também deriva da abordagem de Sistema de Inovação (SI). Porém, diferentemente da abordagem de SSI, esta está centrada em uma tecnologia específica (enfatizando uma dada área tecnológica). Essa abordagem surgiu da necessidade de um arcabouço conceitual para análises relacionadas a áreas tecnológicas na Suécia (CARLSSON, 1995).

Os STI podem ser conceituados como "rede ou redes de agentes interagindo em uma área tecnológica específica sob uma infra-estrutura institucional particular para gerar, difundir e utilizar tecnologia", em que "os sistemas tecnológicos são definidos em termos dos fluxos de conhecimento e capacitações ao invés de fluxos de bens e serviços ordinários" (CARLSSON; JACOBSSON, 1997: 268).

No entanto, a abordagem de STI apresenta algumas vantagens e desvantagens em relação aos SSI, dependendo do foco de análise da estrutura: a abordagem de STI foca em apenas uma tecnologia, a qual está relacionada a diversos setores econômicos (cross-sectors), enquanto a abordagem de SSI foca em apenas um setor, o qual está relacionado com diversas tecnologias (crosstecnologies). É claro que a escolha de uma ou de outra abordagem específica está sempre baseada nos objetivos do estudo em questão e em suas perspectivas.

\section{A pesquisa}

A estrutura metodológica deste trabalho está dividida em duas partes distintas que possuem estreita relação entre si: o arcabouço teórico e metodologia analítica e a metodologia de coleta de dados. O arcabouço teórico consiste em elementos extraídos da literatura da área para compor um modelo híbrido. Em virtude das peculiaridades da aglomeração industrial estudada, utilizam-se elementos da abordagem de clusters e da abordagem de sistemas de inovação (setoriais e tecnológicos). A metodologia analítica descreve a estratégia de análise dos dados, tendo por base o modelo híbrido. Duas dimensões-chave provenientes do modelo compõem a estrutura analítica dos dados empíricos: a estrutura de conexões de conhecimento, utilizada para implementação das mudanças tecnológicas e a postura tecnológica (comportamento ou atitude da firma frente à tecnologia a ser por ela implementada, que pode ser mera usuária, capaz de realizar adaptações menores, de projeto, ou pode ainda ser capaz de inovar em relação àquela tecnologia - esta última representa a situação na qual a firma desenvolve capacitações tecnológicas inovadoras para dominar e manipular essa tecnologia) das firmas que as implementaram, conforme descrito no item 3.1. A metodologia de coleta de dados apresenta uma estratégia peculiar de análise de inovações e de mudanças tecnológicas, além do método empregado para a seleção das firmas da aglomeração industrial para o estudo empírico, conforme descrito no item 3.2.

\subsection{Arcabouço teórico e metodologia de análise de dados}

Devido à limitação das abordagens existentes na literatura de apresentar, de forma isolada, uma estrutura analítica que satisfaça estudos em aglomerações industriais tecnologicamente dinâmicas, foi desenvolvido um modelo híbrido (Figura 1), que utiliza elementos da abordagem de clusters (GIULIANI, 2004) e de sistemas de inovação - setorial e tecnológico (FREEMAN, 1995; MALERBA, 2004; CARLSSON, 1995), em virtude da necessidade de captar dimensões complexas como: territorialidade, aprendizagem, capacitações tecnológicas, mudanças tecnológicas e inovações.

Com base no modelo híbrido proposto, duas dimensões-chave foram determinadas, tomando por base as abordagens escolhidas para a análise da aglomeração. São elas: as conexões de conhecimento (originárias dos estudos que utilizam a abordagem de clusters), e a postura tecnológica das firmas (originária dos estudos que utilizam a abordagem de sistemas de inovação, tanto setoriais quanto tecnológicos).

Como visto anteriormente, as conexões de conhecimento podem ser classificadas em: intra e 


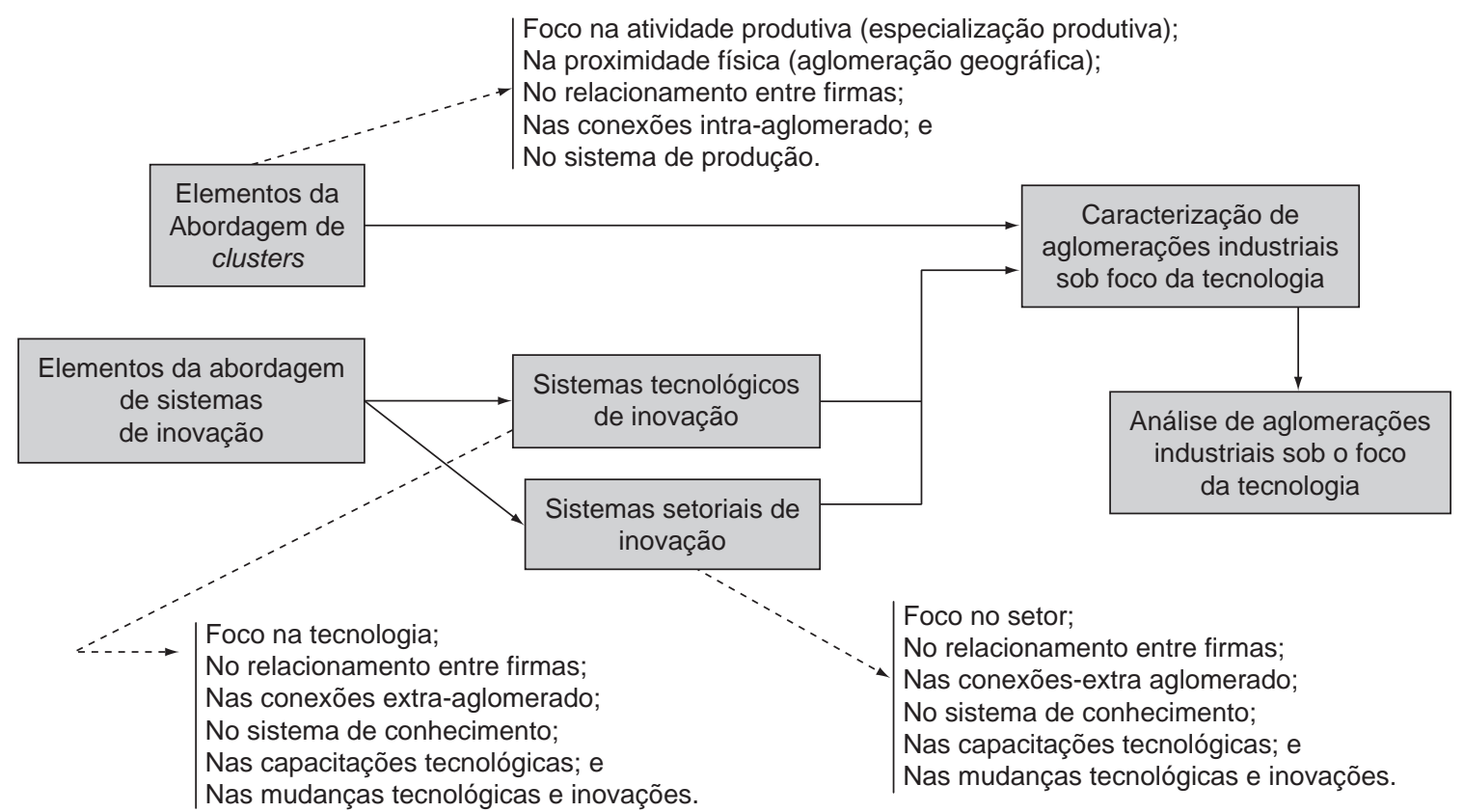

Figura 1. Esquematização estrutural do modelo híbrido.

extra-aglomerado. Quando uma estrutura de conexões é classificada como conectada internamente, significa dizer que existem conexões de conhecimento com atores (fornecedores, compradores, concorrentes, institutos de pesquisa, universidades, associações, etc), que estão presentes dentro da aglomeração industrial. Quando essas conexões internas à aglomeração não são verificadas em determinado evento, sua estrutura é classificada como não-conectada internamente. Do mesmo modo, quando uma estrutura é classificada como conectada externamente, significa dizer que existem conexões de conhecimento com atores (fornecedores, compradores, concorrentes, institutos de pesquisa, universidades, associações, etc), que estão presentes fora da aglomeração industrial, o que se conceitua como uma estrutura de conexões (ou sistema) de conhecimento aberta. Atores fora da aglomeração podem estar dentro do território nacional, ou até mesmo em outros países. Quando essas conexões externas à aglomeração não são verificadas em determinado evento, sua estrutura é classificada como não-conectada externamente, ou estrutura de conexões (ou sistema) de conhecimento fechada (Quadro 1).

A segunda dimensão-chave (Quadro 2), permite entender como se pode classificar a postura tecnológica das empresas em relação às tecnologias utilizadas na implementação das mudanças tecnológicas (eventos). As empresas podem apresentar quatro tipos diferentes de posturas: a) apenas usuárias da tecnologia; b) capazes de realizar adaptações e mudanças de menor significância na tecnologia; c) capazes de realizar mudanças incrementais e de projeto na tecnologia; e d) capazes de inovar (ATHREYE, 2001; BALDWIN; HANEL, 2003; FIGUEIREDO, 2003).

Na primeira postura, as firmas são apenas usuárias da tecnologia, importando-a de algum lugar fora da firma e utilizando-a sem grandes adaptações. Nessa postura, a tecnologia é vista como uma "caixa-preta", sobre a qual o usuário tem pouco ou nenhum conhecimento. A assistência técnica especializada é proveniente de outras firmas, e qualquer alteração na tecnologia vem, predominantemente, de recursos extrafirma. No segundo caso, a firma que utiliza a tecnologia é capaz de realizar pequenas adaptações e mudanças de menor significância na tecnologia que também é proveniente de algum lugar fora da firma (ambiente externo). A assistência técnica e outros serviços também são provenientes de recursos externos à empresa, ainda que a firma possua um pouco mais de domínio tecnológico em relação ao primeiro caso. No terceiro caso, a firma já é capaz de desenvolver e implementar inovações incrementais e mudanças de projeto na tecnologia utilizada. Alguma assistência técnica ainda é necessária para itens de maior conteúdo tecnológico, visto que a tecnologia é proveniente de algum lugar fora da firma (ambiente externo), embora a firma em questão possua condições de modificá-la, já que possui o domínio parcial sobre a mesma. No último caso, a firma domina totalmente a tecnologia em questão e é capaz de inovar, utilizando-se de sua base de conhecimento já adquirido e internalizado pelo processo de absorção de capacitações tecnológicas. Nesse caso, a tecnologia pode ser modificada até mesmo de forma radical, tomando por base os recursos internos à firma. 
Quadro 1. Estrutura das conexões de conhecimento.

\begin{tabular}{|c|c|c|c|}
\hline \multicolumn{2}{|c|}{ Estrutura de conexões } & \multicolumn{2}{|c|}{ Externamente } \\
\hline & & Aberta & Fechada \\
\hline \multirow[t]{2}{*}{ Internamente } & Conectada & $\begin{array}{l}\text { Estrutura conectada com atores do } \\
\text { ambiente interno à aglomeração } \\
\text { industrial e conectada com atores } \\
\text { do ambiente externo à aglomera- } \\
\text { ção (estrutura ou sistema aberto). }\end{array}$ & $\begin{array}{l}\text { Estrutura conectada com atores } \\
\text { do ambiente interno à aglome- } \\
\text { ração industrial e não-conectada } \\
\text { com atores do ambiente externo à } \\
\text { aglomeração (estrutura ou sistema } \\
\text { fechado). }\end{array}$ \\
\hline & Não-conectada & $\begin{array}{l}\text { Estrutura não-conectada com } \\
\text { atores do ambiente interno à aglo- } \\
\text { meração industrial e conectada } \\
\text { com atores do ambiente externo à } \\
\text { aglomeração (estrutura ou sistema } \\
\text { aberto). }\end{array}$ & $\begin{array}{l}\text { Estrutura não-conectada com ato- } \\
\text { res do ambiente interno à aglome- } \\
\text { ração industrial e não-conectada } \\
\text { com atores do ambiente externo à } \\
\text { aglomeração (estrutura ou sistema } \\
\text { fechado). }\end{array}$ \\
\hline
\end{tabular}

Fonte: Silvestre (2006).

Quadro 2. Relação entre as firmas e a tecnologia utilizada: posturas tecnológicas das firmas.

\begin{tabular}{|c|c|}
\hline Postura tecnológica & Característica \\
\hline $\begin{array}{l}\text { Apenas usuária } \\
\text { da tecnologia }\end{array}$ & $\begin{array}{l}\text { Apenas utiliza uma tecnologia } \\
\text { desenvolvida em algum outro lugar. } \\
\text { Pode não ter interesse ou capacidade } \\
\text { de desenvolver/absorver capacitações } \\
\text { tecnológicas para fazer adaptações na } \\
\text { tecnologia em questão. }\end{array}$ \\
\hline $\begin{array}{l}\text { Capaz de realizar } \\
\text { adaptações menores }\end{array}$ & $\begin{array}{l}\text { É capaz de realizar adaptações } \\
\text { menores, no entanto, ainda detém } \\
\text { insuficiente domínio sob a tecnologia } \\
\text { em questão. Pode não ter interesse } \\
\text { ou capacidade para desenvolver as } \\
\text { capacitações tecnológicas inovadoras } \\
\text { necessárias. }\end{array}$ \\
\hline $\begin{array}{l}\text { Capaz de realizar } \\
\text { adaptações maiores } \\
\text { ou de projeto }\end{array}$ & $\begin{array}{l}\text { É capaz de realizar adaptações maio- } \\
\text { res ou de projeto, detendo razoável } \\
\text { domínio sob a tecnologia em questão. } \\
\text { Possuem capacitações tecnológicas } \\
\text { para inovar de forma incremental nas } \\
\text { características estuturais do produto/ } \\
\text { serviço ou processo. }\end{array}$ \\
\hline Capaz de inovar & $\begin{array}{l}\text { É capaz de realizar inovações, até } \\
\text { mesmo radicais, detendo domínio } \\
\text { total sobre a tecnologia em questão. } \\
\text { Possuem capacitações tecnológicas } \\
\text { inovadoras relacionadas a essa } \\
\text { tecnologia. }\end{array}$ \\
\hline
\end{tabular}

Fonte: Silvestre (2006).

O termo capacitações tecnológicas é utilizado, para efeito deste trabalho, no sentido utilizado por Figueiredo (2003), como os recursos necessários para gerar e administrar mudanças tecnológicas, tais como: aptidões, conhecimento e experiências, e sistemas organizacionais. Segundo o autor, a desagregação dos diferentes tipos de capacitações tecnológicas, foi primeiramente desenvolvida por Lall (1992), e utilizada com sucesso por Bell e Pavitt (1995). Essa desagregação faz a distinção entre as capacitações tecnológicas "rotineiras", conceituadas como as aptidões necessárias para usar a tecnologia, o conhecimento e os mecanismos organizacionais, e as capacitações tecnológicas "inovadoras", que consistem em aptidões que permitem criar, modificar ou aperfeiçoar produtos e processos.

Além das duas dimensões-chave; estrutura de conexões de conhecimento e posturas tecnológicas das firmas, a intensidade de cada uma das conexões de conhecimento identificadas no estudo empírico foi também analisada (Quadro 3). Essa variável é importante em virtude de não ser relevante apresentar inúmeras conexões de conhecimento, se as mesmas não possuem intensidade forte ou moderada. Pode ser mais interessante para a firma possuir poucas conexões de conhecimento fortes, do que muitas conexões de conhecimento fracas (ATHREYE, 2001; BALDWIN; HANEL, 2003; FIGUEIREDO, 2003).

Portanto, a postura tecnológica apresentada e as intensidades das conexões de conhecimento, que compõem o sistema de conhecimento, podem estar permitindo que a firma seja capaz de fazer adaptações menores, adaptações de projeto ou até inovações nas tecnologias utilizadas (SILVESTRE, 2006).

A Figura 2 mostra a confrontação entre a estrutura de conexões de conhecimento internas e externas ao aglomerado e a postura tecnológica das firmas para se proceder à análise dos dados. Os eventos que forem localizados na linha A terão uma estrutura de conexões tanto intraaglomerado quanto extra-aglomerado presente. A linha B representará os eventos nos quais existem apenas estruturas de conexão intra-aglomerado. A linha C representará os eventos que apresentam apenas estruturas de conexão extra-aglomerado. Já a linha D representará os eventos sem nenhum tipo de conexão. Em relação às colunas, a coluna 1 representa os eventos nos quais o implementador da mudança tecnológica é apenas usuário daquela tecnologia, a coluna 2 nos quais este implementador é capaz de realizar adaptações menores, a coluna 3 nos quais é capaz 
Quadro 3. Intensidade das conexões de conhecimento.

\begin{tabular}{|c|c|}
\hline Grau de intensidade & Características \\
\hline Forte & $\begin{array}{l}\text { Conexão relacionada com estabelecimento de instrumentos de cooperação formais em P\&D (contratos). O es- } \\
\text { tabelecimento deste tipo de conexão demonstra um esforço deliberado para dominar a tecnologia em questão. } \\
\text { A aquisição de conhecimento e capacitações tecnológicas é intensa. }\end{array}$ \\
\hline Moderada & $\begin{array}{l}\text { Conexão relacionada com políticas de treinamento de técnicos e engenheiros no Brasil e no exterior, incorpo- } \\
\text { rando as capacitações tecnológicas à base de conhecimento da firma. O estabelecimento deste tipo de conexão } \\
\text { demonstra uma postura mais ativa do que passiva da firma. A aquisição de conhecimento e capacitação tecno- } \\
\text { lógicas é moderada. }\end{array}$ \\
\hline Fraca & $\begin{array}{l}\text { Conexão relacionada com a contratação de consultorias técnicas especializadas, tanto nacionais como estran- } \\
\text { geiras. O estabelecimento deste tipo de conexão demonstra uma postura mais passiva do que ativa. A aquisição } \\
\text { de conhecimento e capacitações tecnológicas é pequena. }\end{array}$ \\
\hline Muito fraca & $\begin{array}{l}\text { Conexão relacionada com a troca de informações e conhecimento tecnológico informalmente. O estabeleci- } \\
\text { mento deste tipo de conexão demostra uma postura passiva, sem o esforço deliberado da firma em incorporar } \\
\text { esse conhecimento de forma sistemática. A aquisição de conhecimento e capacitações tecnológicas é muito } \\
\text { pequena. }\end{array}$ \\
\hline
\end{tabular}

Fonte: Silvestre (2006).

\begin{tabular}{|c|c|c|c|c|}
\hline \multicolumn{5}{|c|}{ Estrutura das conexões } \\
\hline $\begin{array}{l}\text { Internamente } \\
\text { conectada e } \\
\text { externamente aberta }\end{array}$ & A1 & A2 & A3 & A4 \\
\hline $\begin{array}{l}\text { Internamente } \\
\text { conectada e } \\
\text { externamente fechada }\end{array}$ & B1 & B2 & B3 & B4 \\
\hline \multirow{3}{*}{$\begin{array}{l}\text { Internamente } \\
\text { não-conectada e } \\
\text { externamente aberta } \\
\text { Internamente } \\
\text { não-conectada e } \\
\text { externamente fechada }\end{array}$} & C1 & C2 & C3 & C4 \\
\hline & D1 & D2 & D3 & D4 \\
\hline & $\begin{array}{l}\text { Apenas } \\
\text { usuários }\end{array}$ & $\begin{array}{c}\text { Adaptações } \\
\text { menores }\end{array}$ & $\begin{array}{c}\text { Adaptações } \\
\text { de projeto }\end{array}$ & $\begin{array}{c}\text { Capaz de } \\
\text { inovar }\end{array}$ \\
\hline
\end{tabular}

Figura 2. Conexões intra e extra-aglomerado $x$ postura tecnológica. Fonte: Silvestre (2006).

de realizar adaptações de projeto naquela tecnologia e a coluna 4 nos quais estes são capazes de inovar.

A parte hachurada, representada pelos quadrantes A3, A4, B3 e B4, são as posições que apresentam tendência de influência da aglomeração (pois são estruturas intensamente conectadas), contribuindo, assim, para uma postura mais direcionada para o desenvolvimento e utilização de capacitações tecnológicas inovadoras (firmas capazes de realizar adaptações de projeto e inovações nas tecnologias utilizadas) e, conseqüentemente, para a inovação.

A partir desta metodologia, é possível elencar algumas considerações importantes acerca de aspectos como: proximidade geográfica e inovação, conforme discutido na seção 4.

\subsection{Metodologia de coleta de dados}

Neste estudo, o método de pesquisa adotado foi o estudo de caso, porque este tipo de abordagem se mostra útil na investigação de fenômenos contemporâneos dentro do contexto da vida real, especialmente quando as fronteiras entre o fenômeno e o contexto não são claramente evidentes (YIN, 2003).

Sob este método, foram realizados dez estudos de caso em firmas atuantes em áreas de intenso dinamismo tecnológico, localizadas na aglomeração (Apêndice I).

A estratégia de conduzir múltiplos estudos de caso envolveu dois grupos de fornecedores do aglomerado estudado. O primeiro grupo é composto de firmas fornecedoras de serviços de poço (instalação, manutenção e reparo de sistemas de cabeça de poço e estruturas de poço, além de fornecimento de outras soluções em tecnologia de poço). O segundo grupo é composto por firmas fornecedoras de equipamentos para a cabeça de poço, mais especificamente árvores de natal molhadas (ANM). Além desses grupos, a Petrobras foi alvo da pesquisa de campo, em virtude de sua peculiar importância dentro da aglomeração.

A coleta de dados foi realizada tendo como recursos fontes de dados, tanto primárias quanto secundárias. A principal técnica de coleta de dados utilizada foi a de entrevista presencial (Apêndice II). As entrevistas foram realizadas com informantes-chave, os quais foram escolhidos entre aqueles com maior contato com a tecnologia utilizada dentro das firmas. Algumas vezes as entrevistas foram realizadas com diretores, gerentes de base, gerentes de tecnologia ou engenheiros experientes. Além disso, foi possível coletar outras informações valiosas relativas a este estudo, por meio de contatos e conversas informais com outros empregados das empresas e por meio da observação direta. Os dados secundários foram adquiridos através de pesquisa em publicações anuais das empresas, publicações das instituições de apoio (associações, organizações), jornais e revistas especializadas, internet, etc. Além disso, a coleta de dados foi fundamental para a determinação do processo de formação, bem como a caracterização deste aglomerado industrial, sob a ótica da tecnologia. 
As firmas analisadas neste estudo foram escolhidas tendo por base o cadastro de fornecedores da ONIP (Organização Nacional da Indústria de Petróleo), tanto nacionais como multinacionais, mas com uma característica em comum: fornecedores de bens e serviços de significativa complexidade tecnológica, atuando em áreas com relevante dinamismo tecnológico. Esta escolha está baseada nas características da própria aglomeração e em informações coletadas junto ao IBP (Instituto Brasileiro de Petróleo), à Rede-Petro (rede de empresas do aglomerado de petróleo e gás estudado), à Petrobras e à própria ONIP. Em algumas ocasiões, o IBP, a ONIP e a própria Petrobras foram responsáveis pela indicação e pelo primeiro contato com as firmas, permitindo, assim, um maior respaldo e a abertura das mesmas para a realização das entrevistas. Com essa estratégia, buscou-se concentrar o foco em firmas cuja tecnologia representa um fator relevante nos bens e serviços comercializados.

A unidade de coleta de dados consiste nas mudanças tecnológicas implementadas por essas firmas na aglomeração industrial. Essa estratégia foi adotada no sentido de fornecer praticidade na referida fase. Na ocasião das entrevistas o foco foi direcionado para eventos tecnológicos específicos (mudanças tecnológicas implementadas) e não para a firma como um todo, conforme metodologia usada por Baldwin e Hanel (2003). Os eventos foram identificados pelo próprio entrevistado (informantechave), representando, portanto, as principais mudanças tecnológicas implementadas nos últimos anos por aquela empresa na aglomeração. Na medida do possível, a importância dos eventos foi checada com outros funcionários das firmas, com suas concorrentes e com a própria Petrobras, em entrevista subseqüente. Tal estratégia ajudou a atenuar alguns problemas identificados antes do trabalho empírico: o pequeno número de empresas em cada grupo e o receio de perder o foco no momento das entrevistas. Assim, pôde-se aumentar o número de pontos de análise (por meio dos eventos) e direcionar a entrevista para um único evento, o que aumentou a precisão das respostas.

A importância da estratégia utilizada fica evidente, já que se realizaram entrevistas em apenas 10 firmas, mas seguindo a estratégia com foco nas mudanças tecnológicas implementadas pelas firmas, pôde-se determinar 25 (vinte e cinco) eventos válidos no total, sendo que cada uma das firmas identificou entre 1 (um) e 4 (quatro) eventos tecnológicos. Nos 25 eventos estudados, foram identificadas 75 conexões de conhecimento estabelecidas para que as mudanças tecnológicas pudessem ser implementadas no aglomerado (variando de 1 a 5 conexões em cada um dos eventos). Dessa forma, é possível afirmar que a contribuição dos casos estudados, focando em eventos tecnológicos específicos, foi muito importante para o desenvolvimento do trabalho. No entanto, não seria possível dizer ainda que este é o caminho para a construção de uma teoria fundamentada na prática.

\subsection{Resultados de pesquisa}

Os resultados da pesquisa representam produtos da pesquisa documental, da revisão bibliográfica das principais abordagens utilizadas e da pesquisa de campo. Estes resultados foram divididos em dois blocos: a formação e a caracterização da Aglomeração Industrial, estes consistem nos objetivos específicos deste estudo e nos resultados dos dez estudos de caso realizados em firmas localizadas na aglomeração.

\subsubsection{Formação e caracterização da aglomeração industrial}

A formação da aglomeração industrial de petróleo e gás da região produtora da Bacia de Campos (BC) ocorreu de uma maneira gradual, acompanhando a evolução das descobertas dos campos petrolíferos na $\mathrm{BC}$, e tendo como mola mestra para seu surgimento e desenvolvimento, a Petrobras.

O descobrimento de campos petrolíferos na $\mathrm{BC}$ aconteceu em 1974, com o campo petrolífero de Garoupa. A partir deste momento, e com as constantes descobertas de novos campos, essa região se tornou um pólo de atração de firmas das mais diferentes naturezas, atuantes direta e indiretamente na indústria do petróleo.

Em um primeiro momento, ocorre a fixação de unidades da Petrobras na área para viabilizar o acesso de técnicos e estrutura para iniciar o desenvolvimento dos primeiros campos petrolíferos descobertos na Bacia. Esse foi um processo gradual e se intensificou na medida em que a viabilidade econômica dos campos descobertos foi se mostrando positiva.

Nesse processo de fixação da Petrobras ocorreu a atração das firmas fornecedoras diretas da Petrobras. As primeiras firmas que estabeleceram bases na região, depois da Petrobras, foram os fornecedores de bens e serviços de maior complexidade tecnológica (que firmaram contratos de longo prazo com a operadora). Muitas dessas empresas não possuíam subsidiárias no Brasil e começaram a migrar para este país, em decorrência do aumento significativo das encomendas da Petrobras. A partir deste momento inicial, inúmeras outras firmas migraram de diversas regiões do país e do mundo para a região, atraídas não só pela presença da Petrobras, mas também pela presença de outros grandes fornecedores internacionais. Outras tantas firmas nasceram por meio de empreendedores da região, com o objetivo de atuarem em nichos de mercado abertos pela presença das empresas da indústria do petróleo.

Percebe-se, assim, que o papel da Petrobras na formação da aglomeração é central. Esse papel continua sendo fundamental hoje em dia nas atividades da aglomeração, em virtude de se identificar uma presença ainda 
tímida das grandes operadoras de petróleo mundiais na aglomeração, e até mesmo em atividades de E\&P offshore no território nacional, na maioria das vezes por meio de parcerias com a própria Petrobras. A configuração resultante deste processo é uma extensa estrutura de fornecimento, onde existem diversos níveis, de acordo com a complexidade e grau de responsabilidade da firma. Pode-se afirmar ainda, que existe uma estratificação do ponto de vista tecnológico dentro da aglomeração. Sob este recorte, podem ser apontados quatro diferentes grupos de firmas presentes no aglomerado: a) firmas operadoras de petróleo e gás (demandantes dos bens e serviços); b) firmas fornecedoras de bens e serviços offshore de alta complexidade tecnológica; c) firmas fornecedoras de bens e serviços offshore de moderada complexidade tecnológica; e d) firmas fornecedoras de bens e serviços de apoio de baixa complexidade tecnológica. Existe ainda um quinto grupo formado por instituições de apoio às firmas localizadas na aglomeração industrial de petróleo e gás da região produtora da $\mathrm{BC}$ (Figura 3 ).

No primeiro grupo, além da Petrobras, existem ainda outras onze operadoras de campos de petróleo e gás localizadas na aglomeração, exercendo atividades de E\&P offshore, mas com muito menor intensidade, se comparadas com as atividades da Petrobras. As firmas operadoras presentes na aglomeração são, além da Petrobras, a Total Fina Elf, Shell (Enterprise), Exxon Mobil, Pan Canadian, Repsol-YPF, Wintershull, Devon, ChevronTexaco, Agip,

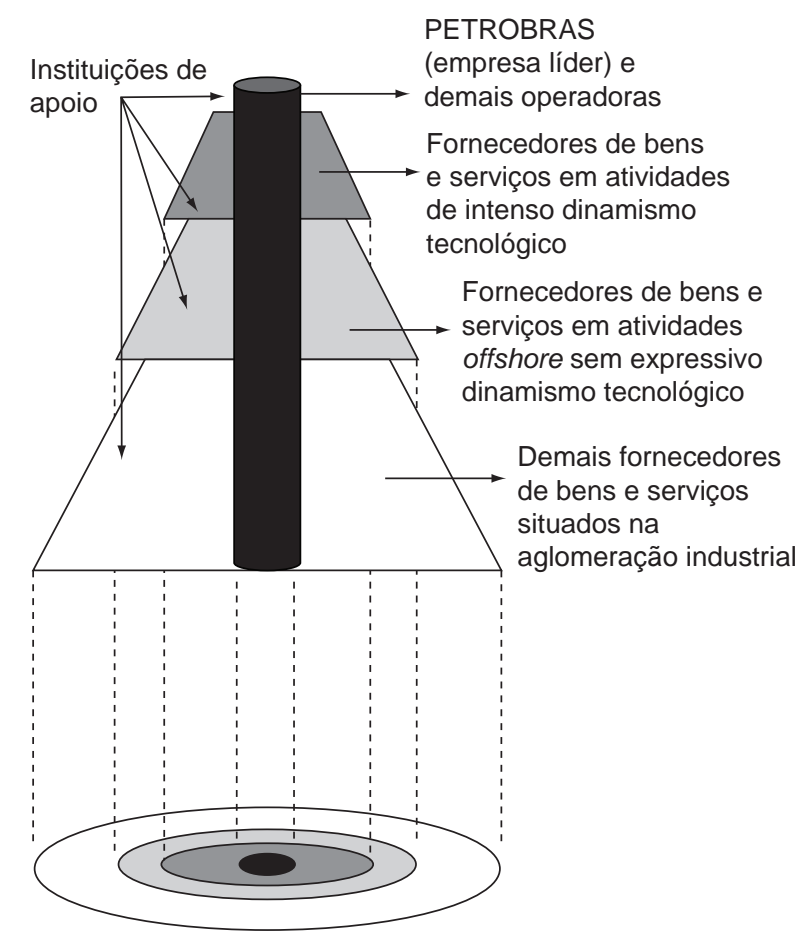

Figura 3. Caracterização do aglomerado de petróleo e gás, segundo o grau de complexidade e dinamismo tecnológico das firmas. Fonte: Silvestre (2006).
Unocal e Ocean Energy INC. Destas onze operadoras de petróleo e gás estrangeiras, nove delas apresentam projetos de E\&P com a própria Petrobras (SILVA, 2004). Em relação à tecnologia, pode-se afirmar que estas empresas são dinâmicas e atuam em áreas de fronteira do conhecimento humano, demandando, por isso, intensos e constantes esforços de $\mathrm{P} \& \mathrm{D}$ em novos produtos e novas tecnologias.

O segundo grupo é composto por cerca de 50 fornecedores de bens e serviços offshore de alta complexidade tecnológica, atuando em áreas de intenso dinamismo tecnológico, possuindo grande poder de barganha com as empresas demandantes (Petrobras e outras). Sem a presença dessas empresas na província da $\mathrm{BC}$ e no Brasil, a Petrobras provavelmente não seria capaz de desenvolver 'sozinha' as atividades de exploração e produção de petróleo e gás. É neste grupo que se encontra o foco do trabalho. Este grupo pode ainda ser dividido, a grosso modo, nos seguintes subgrupos: prospecção (serviços de geologia de superfície, aerofotogrametria, magnetometria, gravimetria e estudos sísmicos, realizados em modernos navios de exploração e análise de dados que auxiliam detectar a presença do óleo e do gás nas profundezas do oceano, em tecnologia 3D e 4D), perfuração (serviços de colunas de perfuração e operações de perfuração), fornecedores de equipamentos de poço (árvores de natal molhadas, manifolds, equipamentos para bombeio do óleo e/ou do gás e sistemas e equipamentos de segurança de poço e prevenção de acidentes, entre outras), fornecedores de serviços de poço (soluções em tecnologia de poço, tais como completação e cimentação de poços, perfilagem de poços, testes de pressão, tecnologia de fluidos, condicionamento e estimulação de poços, sistemas de bombeio, entre outros), serviços e equipamentos offshore (serviços e equipamentos relacionados a ROV's - remoted operated vehicles - e outros equipamentos e serviços offshore caracterizados por intenso dinamismo tecnológico).

Sob condições diferentes, encontra-se o terceiro grupo, composto pelas outras empresas que fornecem bens e serviços para atividades offshore, mas sem expressiva complexidade e dinamismo tecnológico. Este grupo é composto pelos fornecedores de equipamentos e serviços de segurança em geral (EPI's - equipamentos de proteção individual e EPC's - equipamentos de proteção coletiva), firmas de manutenção preventiva e reparos em sistemas e equipamentos elétricos (geradores, bombas, etc), firmas de mergulho, firmas fornecedoras de serviços de calderaria, soldagem, de transporte marítimo (em embarcações) e aéreo (em helicópteros) para as unidades de produção no mar, entre outras.

No quarto grupo, atuando sob condições menos favoráveis que os dois grupos de fornecedores anteriores, estão as firmas fornecedoras de bens e serviços de apoio 
às atividades offshore. Essa situação acontece por fornecerem bens e serviços auxiliares e que não estão situados nas áreas essenciais das compradoras. São firmas que fornecem desde serviços de limpeza, até mantimentos e serviços de cozinha (catering), hotelaria, segurança predial e de instalações industriais, material e mobiliário para escritórios, serviços de seguros, entre outros.

Portanto, esta estratificação da aglomeração industrial em grupos diferenciados, segundo o grau de complexidade tecnológica dos bens e serviços fornecidos e das áreas de maior dinamismo tecnológico, é fundamental para fornecer as bases para outros trabalhos (tanto nesta aglomeração, quanto em outras igualmente dinâmicas tecnologicamente) e para o entendimento da aglomeração sob estes dois importantes aspectos: a complexidade tecnológica dos bens e serviços fornecidos e o dinamismo tecnológico das firmas.

\subsubsection{Resultados dos estudos de caso}

O trabalho de campo nas dez firmas, conforme já mencionado, gerou 25 eventos válidos (mudanças tecnológicas), conforme Quadro 4.

Alguns exemplos de eventos considerados podem ser destacados para efeito de ilustração, tais como o HRMF (Horizontal Revestido Multi-Fraturado), equipamento que propiciou: grandes benefícios na estimulação de poços de petróleo e o melhor aproveitamento do óleo ali localizado (otimizando a produção dos poços), o desenvolvimento de Sistema de Controle Multiplexado (SCM), que permite o controle eletrônico das válvulas localizadas a $3.000 \mathrm{~m}$ de profundidade (considerando as especificidades das condições das marés, das características da água, da temperatura e da pressão a que o equipamento era submetido), e do Sistema de Controle Acústico (SCA), eliminando a utilização de umbilical (cabos de contato com o equipamento submerso), ainda em fase de testes. Os eventos (mudanças tecnológicas) são identificados e descritos de forma sucinta e levando em conta as questões relativas ao sigilo, que em alguns casos foi solicitado pelas firmas. Nesses casos, os eventos consistem em projetos avançados para serem implementados futuramente na província petrolífera, conforme Apêndice III.

Conforme a Figura 4, dos 25 (vinte cinco) eventos tecnológicos estudados, 11 (onze) - 44\% (plotados na área hachurada) - apresentam evidências de que o domínio tecnológico (o que leva a firma a inovar) seja influenciado positivamente pelo fato das firmas estarem aglomeradas em um mesmo espaço geográfico. Por outro lado, $56 \%$ dos eventos não apresentam evidências de que essa influência aconteça, por consistirem em estruturas sem conexões com atores localizados dentro da aglomeração ou por possuírem pequeno domínio em relação à tecnologia.

Em relação ao eixo horizontal, constatou-se que dos vinte e cinco (25) eventos analisados no estudo empírico, 4 (quatro) - 16\% - apresentam postura de apenas usuários da tecnologia em questão (coluna 1 da Figura 4). As firmas inseridas nesta coluna não possuem domínio da tecnologia. Nesses eventos $(11,13,14$ e 25$)$, ou as firmas

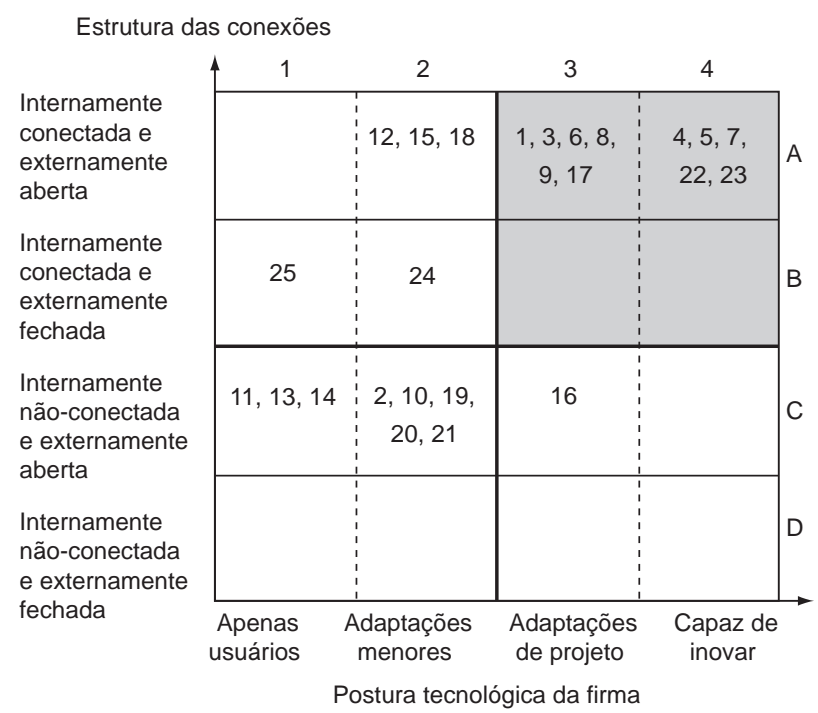

Figura 4. Plotagem dos eventos (conexões de conhecimento $\mathrm{x}$ postura tecnológica).

Quadro 4. Eventos válidos por empresa.

\begin{tabular}{llccc}
\hline \multicolumn{1}{c}{ Grupos } & \multicolumn{1}{c}{ Firmas } & Eventos & Código do evento & Total eventos/subgrupo \\
\hline Fornecedores de & Cooper Cameron & 2 & 1 e 2 & 9 \\
equipamentos (ANM) & VetcoGray & 3 & 3,4 e 5 & 6 \\
& Aker Kvaener & 1 & 7,8 e 9 & 10 e 11 \\
Fornecedores de & FMC Technologies & 3 & 12 e 13 & 12 e 15 \\
serviços de poço & Baker Huges & BJ Services & 2 & 16,17 e 18 \\
(Well Technology) & Schlumberger & 2 & 19,20 e 21 & 4 \\
& Weatherford & 3 & $22,23,24$ e 25 & \\
\hline
\end{tabular}


não são capazes de alterarem a tecnologia, ou não têm interesse nessa atividade. No primeiro caso, as firmas não possuem meios de 'dominar' a tecnologia, tendo em vista sua capacidade de absorção de capacitações tecnológicas. No segundo caso, as firmas preferem contratar uma outra firma para fornecer essa tecnologia, não se preocupando em absorver o conhecimento intrínseco na mesma, por não ser este o foco de interesse. Essa tecnologia pode ser proveniente, em alguns casos, de subsidiárias ou matrizes da firma fora do aglomerado. Com relação a essa situação, a base da firma na aglomeração pode não possuir as capacitações tecnológicas necessárias para inovar, por questões políticas internas à companhia (não há interesse em investir em absorção de capacitações tecnológicas inovadoras na província). As tecnologias são desenvolvidas, portanto, fora da aglomeração, onde a companhia mantém seus centros de P\&D. A base da companhia localizada na província é um agente executor de tarefas (apenas implementador de mudanças tecnológicas).

Dos vinte e cinco (25) eventos analisados no estudo empírico, 9 (nove) - 36\% - apresentam postura de serem capazes de realizar apenas adaptações menores na tecnologia em questão (coluna 2 da Figura 4). As firmas inseridas nesta coluna possuem pouco domínio da tecnologia em questão no evento. Nesses eventos $(2,10,12$, $15,18,19,20,21$ e 24), as firmas são capazes de alterar a tecnologia apenas de forma superficial (adaptações menores) ou possuem pequeno interesse na mesma.

Do total de eventos analisados no estudo empírico, 7 (sete) $-28 \%$ - apresentam postura de serem capazes de realizar adaptações de projeto na tecnologia em questão (coluna 3 da Figura 4). As firmas inseridas nesta coluna possuem significativo domínio da tecnologia em questão no evento. Nesses eventos (1, 3, 6, 8, 9, 16 e 17), as firmas são capazes de alterar a tecnologia de forma intensa (adaptações de projeto), possuindo interesse significativo na mesma. As firmas possuem significativo domínio da tecnologia em questão, e podem investir ainda mais recursos para aumentar esse domínio tecnológico (evoluindo no eixo horizontal da Figura 4).

Do total de eventos analisados no estudo empírico, 5 (cinco) - 20\% - apresentam postura de serem capazes de inovar na tecnologia em questão (coluna 4 da Figura 4). As firmas inseridas nesta coluna possuem total domínio da tecnologia em questão no evento. Nesses eventos (4, 5, 7, 22 e 23), as firmas são capazes de alterar a tecnologia de forma radical (inovações), possuindo interesse total na mesma. Essas firmas implementaram as mudanças tecnológicas com base em inovações desenvolvidas dentro da firma. A consolidação dessas informações relativas à postura tecnológica das firmas está disposta na Figura 5.

Em relação ao eixo vertical, que estabelece as características das estruturas das conexões de conhecimento, dos 25 eventos, 14 (56\% deles) apresentam uma estrutura de

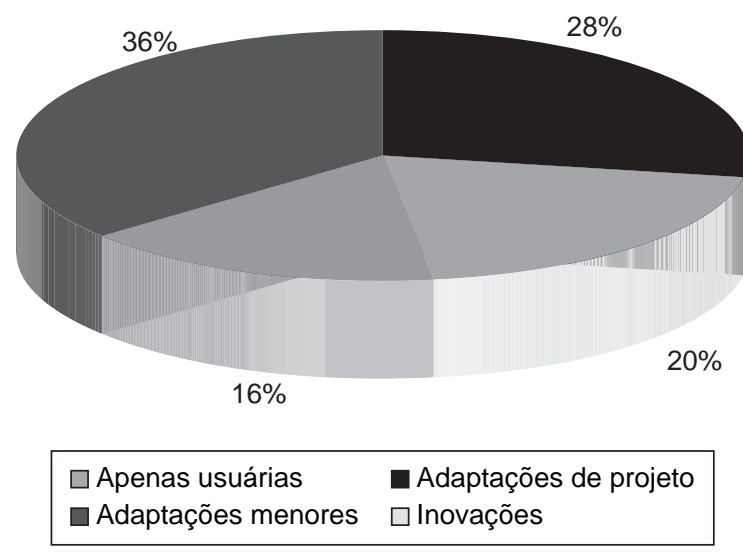

Figura 5. Postura tecnológica das firmas.

conexões internamente e externamente conectada (sistema de conhecimento aberto) - linha A. Nesses eventos (1, 3, $4,5,6,7,8,9,12,15,17,18,22$ e 23 ), observou-se um relacionamento das firmas com organizações localizadas tanto dentro quanto fora da aglomeração industrial.

De forma análoga, 2 dos 25 eventos (8\%) apresentam uma estrutura de conexões de conhecimento internamente conectada e externamente não-conectada (sistema de conhecimento fechado) - linha B. Nesses eventos (25 e 24), observou-se um relacionamento das firmas com organizações localizadas dentro da aglomeração, mas sem conexões com organizações localizadas fora da aglomeração industrial.

Dos 25 eventos tecnológicos estudados, 9 deles (36\%) apresentam uma estrutura de conexões de conhecimento internamente não-conectada e externamente conectada (sistema de conhecimento aberto). Nesses eventos (2, 10, $11,13,14,16,19,20$ e 21), observou-se um relacionamento das firmas com organizações localizadas fora da aglomeração, mas sem conexões com organizações localizadas dentro da aglomeração industrial.

Nenhum dos eventos estudados apresentou inexistência de conexões de conhecimento, ou seja, estrutura internamente e externamente não-conectada, concomitantemente.

A análise das intensidades das conexões apresentou a mesma tendência das estruturas de conexões de conhecimento. Os fornecedores de serviços de poço apresentaram tendência a estabelecerem conexões de conhecimento fortes e moderadas na mesma proporção que conexões fracas e muito fracas. No entanto, as conexões extra-aglomerado possuem uma predominância significativa em relação às conexões intra-aglomerado. Já os fornecedores de equipamentos de poço apresentaram maior número de conexões fortes e moderadas (o que indica uma postura mais ativa em relação à absorção da tecnologia), sendo que metade delas foi estabelecida com atores localizados dentro da própria aglomeração, o que mostra a importância da concentração geográfica para as atividades inovadoras 
(mudanças tecnológicas) das firmas deste grupo. Em relação à Petrobras, o predomínio das conexões de conhecimento intra-aglomerado é nítido, sendo que a maioria delas apresenta intensidades fortes ou moderadas. Conforme salientado anteriormente, foram estudados 25 eventos válidos (mudanças tecnológicas), que apresentaram ao todo 75 conexões de conhecimento (variando de 1 a 5 conexões em cada um dos eventos, conforme Quadro 5).

Voltando à área hachurada (Figura 4), 11 (onze) eventos são ali plotados. Desses eventos que apresentam estrutura de conexões de conhecimento internamente conectada e o uso de capacitações tecnológicas inovadoras, 8 são relativos aos fornecedores de equipamentos de poço, 2 relativos à Petrobras e apenas 1 relacionado aos fornecedores de serviços de poço.

Assim, pode-se identificar que na área onde a proximidade geográfica pode ter influência na postura das firmas (área hachurada - pois existem conexões fortes internas ao aglomerado) existe uma maioria de eventos relacionados a firmas fornecedoras de equipamentos de poço. Nesta área, existe a identificação de conexões de conhecimento intra-aglomerado e de posturas tecnológicas que demonstram um esforço em absorver as tecnologias utilizadas (por meio das conexões estabelecidas) e o uso de capacitações tecnológicas inovadoras (que mostram certo grau de domínio das tecnologias).

\section{Análise e discussão dos resultados}

No estudo empírico, pôde-se perceber que as conexões das firmas localizadas dentro da aglomeração com organizações de fora da aglomeração (conexões de conhecimento extra-aglomerado) se mostram mais numerosas (em 92\% do total dos eventos). Essa situação é, em parte, explicada pelo fato de se tratar de um conjunto de firmas com muitos atores globais, ou seja, firmas multinacionais com intensas conexões de conhecimento extra-aglomerado (estruturas abertas e voltadas para fora do aglomerado - global players).

Assim, constatou-se, de acordo com a célula destacada no Quadro 6, que para algumas firmas as conexões de conhecimento intra-aglomerado (internamente conectadas) favorecem uma postura mais inovadora (uso de capacitações tecnológicas inovadoras).

Quadro 5. Intensidade das conexões de conhecimento.

\begin{tabular}{|c|c|c|c|c|c|}
\hline $\begin{array}{c}\text { Grau de } \\
\text { intensidade }\end{array}$ & Forte & Moderada & Fraca & $\begin{array}{c}\text { Muito } \\
\text { fraca }\end{array}$ & Total \\
\hline $\begin{array}{l}\text { Equipamentos } \\
\text { de poço }\end{array}$ & 25 & 0 & 5 & 11 & 41 \\
\hline $\begin{array}{l}\text { Serviços } \\
\text { de poço }\end{array}$ & 8 & 7 & 19 & 0 & 34 \\
\hline Total & 33 & 7 & 24 & 11 & 75 \\
\hline
\end{tabular}

As firmas que apresentam conexões de conhecimento intra-aglomerado, de intensidades fortes e são capazes de realizarem mudanças de projeto ou inovações na tecnologia representada pelos eventos tecnológicos $(1,3,4,5$, $6,7,8,9,17,22$ e 23), mostram indícios de que a aglomeração pode estar exercendo uma contribuição positiva para o domínio das tecnologias e, conseqüentemente, para a inovação.

De forma contrária, as firmas que possuem poucas conexões de conhecimento intra-aglomerado, de intensidades fortes e são apenas usuárias da tecnologia em questão, representadas pelos eventos tecnológicos, mostram indícios de que a aglomeração pode não estar exercendo uma contribuição tão efetiva para o domínio das tecnologias e, conseqüentemente, para a inovação.

Contudo, do total de nove (9) eventos estudados nas firmas fornecedoras de equipamentos de poço, oito (8) apresentam conexões de conhecimento intra-aglomerado (89\%), conforme Quadro 7. Essa situação indica que as conexões de conhecimento intra-aglomerado (geradas dentro da própria aglomeração) possuem importância significativa para esse grupo de firmas, e que estas firmas desenvolveram algumas capacitações tecnológicas inovadoras (representadas pela segunda dimensão-chave), que as confere o domínio sobre as tecnologias para, conseqüentemente, alterá-las (capazes de realizarem adaptações de projeto e de inovarem).

Do total de doze (12) eventos estudados nas empresas de serviços de poço, apenas 4 (quatro) apresentam conexões de conhecimento intra-aglomerado (33\%), conforme Quadro 8. Essa situação indica que as conexões de conhecimento intra-aglomerado (geradas dentro da própria aglomeração) possuem pouca importância para esse grupo, e que estas firmas desenvolveram apenas capacita-

Quadro 6. Conexões intra-aglomerado e capacitações tecnológicas.

\begin{tabular}{lcc}
\hline & $\begin{array}{c}\text { Capacitações } \\
\text { tecnológicas } \\
\text { rotineiras }\end{array}$ & $\begin{array}{c}\text { Capacitações } \\
\text { tecnológicas } \\
\text { inovadoras }\end{array}$ \\
\hline $\begin{array}{l}\text { Internamente } \\
\text { conectada }\end{array}$ & 5 & $\mathbf{1 1}$ \\
$\begin{array}{l}\text { Internamente não } \\
\text { conectada }\end{array}$ & 8 & 1 \\
\hline
\end{tabular}

Quadro 7. Conexões intra-aglomerado e capacitações tecnológicas (fornecedores de equipamentos).

\begin{tabular}{lcc}
\hline & $\begin{array}{c}\text { Capacitações } \\
\text { tecnológicas } \\
\text { rotineiras }\end{array}$ & $\begin{array}{c}\text { Capacitações } \\
\text { tecnológicas } \\
\text { inovadoras }\end{array}$ \\
\hline $\begin{array}{l}\text { Internamente } \\
\text { conectada }\end{array}$ & 0 & $\mathbf{8}$ \\
$\begin{array}{l}\text { Internamente não } \\
\text { conectada }\end{array}$ & 1 & 0 \\
\hline
\end{tabular}


Quadro 8. Conexões intra-aglomerado e capacitações tecnológicas (fornecedores de serviços).

\begin{tabular}{lcc}
\hline & $\begin{array}{c}\text { Capacitações } \\
\text { tecnológicas } \\
\text { rotineiras }\end{array}$ & $\begin{array}{c}\text { Capacitações } \\
\text { tecnológicas } \\
\text { inovadoras }\end{array}$ \\
\hline $\begin{array}{l}\text { Internamente } \\
\text { conectada } \\
\begin{array}{l}\text { Internamente não } \\
\text { conectada }\end{array}\end{array}$ & 3 & $\mathbf{1}$ \\
\hline
\end{tabular}

ções tecnológicas rotineiras (representadas pela segunda dimensão-chave), que as confere um pequeno domínio sobre as tecnologias, não permitindo, conseqüentemente, alterá-las de forma significativa (sendo apenas usuárias da tecnologia ou capazes de realizarem apenas adaptações menores). Os quatro eventos relativos à Petrobras não foram considerados nos Quadros 7 e 8.

Esses resultados indicam que as firmas fornecedoras de equipamentos de poço apresentam evidências de serem beneficiadas (em aspectos de inovação), pelo fato de estarem agrupadas geograficamente na aglomeração industrial da região produtora da BC. Essa questão é reforçada em virtude de possuírem maior conhecimento das peculiaridades produtivas e operacionais da $\mathrm{BC}$ e serem, portanto, induzidas pela Petrobras a desenvolverem as capacitações tecnológicas inovadoras na própria aglomeração. De forma oposta, as firmas fornecedoras de serviços de poço não apresentam evidências de estarem sendo beneficiadas (em aspectos de inovação), pelo fato de estarem agrupadas na aglomeração industrial. A postura apresentada pela Petrobras, mais ativa em relação às mudanças tecnológicas em equipamentos de poço, e menos ativa em relação às mudanças tecnológicas em serviços de poço, reforça essas evidências.

\section{Considerações finais}

A aglomeração industrial de petróleo e gás da região produtora da $\mathrm{BC}$ consiste em uma concentração geográfica de firmas que atuam nas atividades de E\&P offshore. Sob a liderança da Petrobras, principal operadora de campos petrolíferos, e principal demandante das encomendas ali efetuadas, esta aglomeração industrial apresenta uma estrutura em rede de fornecimento composta de cerca de 1.500 firmas.

A aglomeração industrial apresenta algumas características importantes e distintas das aglomerações industriais tradicionais (clusters) encontradas na literatura e que devem ser destacadas, pois embasam a utilização do modelo híbrido de análise. Apesar das empresas estarem aglomeradas em um mesmo espaço geográfico e possuírem, a grosso modo, a mesma especialização produtiva, apresentam outras características que diferem fortemente dos clusters tradicionais. O fato de haver jazidas de recursos naturais (petróleo e gás) abundantes na Bacia de Campos faz com que haja uma ausência de aspectos relacionados à cultura e tradição da região na atividade de E\&P de petróleo e gás. Na realidade, as firmas estão ali presentes para explorar o recurso existente. Essa característica faz com que esta aglomeração industrial não permita ser analisada somente sob a abordagem tradicional de cluster.

Por esse motivo, outros elementos da abordagem de sistemas de inovação foram também inseridos no modelo híbrido, em virtude da interação entre os atores ser mais focada sob o prisma do conhecimento, das mudanças tecnológicas implementadas e da inovação. Por isso a abordagem de sistemas de inovação, mais especificamente suas variações setorial e tecnológica, também recebeu destaque no modelo híbrido proposto.

Destas duas abordagens teóricas que compõem o modelo híbrido originam-se as duas dimensões-chave que formam o modelo analítico proposto para o estudo empírico. Da abordagem de clusters provém a primeira dimensão-chave (caracterizada no eixo vertical), são as conexões entre firmas. Da abordagem de sistemas de inovação provém a segunda dimensão-chave (caracterizada pelo eixo horizontal), é a postura da firma em relação à tecnologia.

Nos resultados da pesquisa, a formação e a caracterização atual da aglomeração industrial foram alcançadas. A caracterização em relação ao dinamismo tecnológico de seus atores e a complexidade dos bens e serviços fornecidos foi estabelecida com base na estratificação de quatro diferentes grupos de firmas (além das instituições de apoio). Essa estratégia foi adotada em virtude da heterogeneidade dos atores e das dificuldades de se aplicar uma análise à totalidade da aglomeração. A estratégia de se adotar a aglomeração industrial como um objeto de estudo único e homogêneo tecnologicamente, pode levar ao equívoco de se fazer generalizações para toda a aglomeração, resultando em inconsistências e distorções. Apesar do primeiro grupo de firmas ser composto por doze operadoras de campos de petróleo e gás, a Petrobras ainda exerce o papel central na aglomeração, tanto na governança quanto na porcentagem de encomendas realizadas na Bacia de Campos. Essa configuração confere à aglomeração uma estrutura bastante verticalizada, composta de diversos níveis de fornecedores e graus de responsabilidades.

A estrutura de conexões de conhecimento, de modo geral, se mostrou amplamente aberta, com a presença de muitas conexões de conhecimento estabelecidas com atores localizados fora da aglomeração. No grupo de fornecedores de serviços em tecnologia de poço, percebeu-se que essas conexões estão presentes em todos os doze eventos estudados. Destas conexões, a grande maioria foi estabelecida com outras divisões da 
própria companhia, com suas matrizes ou com centros de pesquisa próprios localizados nos EUA ou na Europa. Essa configuração, aliada ao fato de que a postura dessas empresas em relação à tecnologia identificada nos eventos é de apenas 'usuárias' ou capazes de fazer apenas adaptações menores, indicam que essas companhias consistem apenas em executoras de tarefas dentro da aglomeração industrial, utilizando, na maior parte dos eventos, capacitações tecnológicas rotineiras. Já no grupo de firmas fornecedoras de equipamentos de poço, detectou-se também uma vasta malha de conexões de conhecimento extra-aglomerado, mas as conexões de conhecimento intra-aglomerado se apresentam de forma mais intensa do que no grupo anterior, indicando que o fato de estarem geograficamente agrupadas faz diferença neste grupo.

Partindo do princípio que as províncias de petróleo e gás, e conseqüentemente, as aglomerações industriais mais dinâmicas (como Houston-EUA, Aberdeen-UK, Oslo/Stavanger-Noruega, entre outras), possuem ciclos de vida determinados, em virtude da natureza finita das jazidas de petróleo e de gás, pode-se prever que mais cedo ou mais tarde essas províncias se deparem com um processo de declínio de suas atividades. De forma geral, essas províncias possuem em seu ciclo de vida quatro fases distintas: surgimento, crescimento, maturação e declínio. $\mathrm{Na}$ fase de declínio, a produção de petróleo e gás começa a diminuir fazendo com que as empresas localizadas na aglomeração industrial relacionada a esta província migrem para outras províncias mais promissoras.
Nesse contexto, não se pode deixar de falar em políticas de desenvolvimento da aglomeração e na busca de alternativas para as firmas ali localizadas. No sentido de inserir um maior número de firmas nacionais em um contexto mais global da indústria de petróleo e gás, é necessário aproximar as firmas dos grupos de fornecedores de bens e serviços com pouca complexidade tecnológica das grandes firmas multinacionais que apresentam maior complexidade tecnológica em seus bens e serviços. Essa política de parcerias poderia ser a mola mestra para a absorção de novas capacitações tecnológicas inovadoras por parte das empresas locais.

Esse processo pode gerar, no médio/longo prazo, condições para que essas empresas nacionais possam vir a se tornar competentes fornecedoras globais da indústria petrolífera, ou até mesmo, concorrentes das grandes firmas multinacionais localizadas no Brasil e em outras províncias ao redor do mundo. Essa estratégia poderia evitar uma grande recessão regional e o provável colapso da economia local.

Finalmente, como sugestão para trabalhos futuros, pode-se destacar o aprimoramento e a consolidação do modelo híbrido teórico e do modelo analítico, composto pelas duas dimensões-chave. Além disso, a aplicação da metodologia em outras aglomerações industriais, ligadas a províncias petrolíferas, bem como em outros setores econômicos, como o de energia elétrica, o automobilístico, o aeronáutico, entre outros, consistiria em uma linha de pesquisa importante.

\title{
Knowledge linkages and technological approaches of the firms: evidences from the oil and gas industrial agglomeration of the Campos basin
}

\begin{abstract}
The present work analyses the results of empirical research involving ten firms that are part of the oil and gas industrial agglomeration in the productive region of the Campos Basin (RJ). The firms involved in this study operate in areas of intense technological dynamism providing products and services of high technological complexity to operators in this region. Two groups of firms were given special attention: well equipment suppliers (wet Christmas trees) and well service suppliers (well technology). A hybrid model for agglomeration analysis was developed, which uses elements from the clusters approach and innovation systems (sectoral and technological). The aim of this work was to determine the formation process and the agglomeration characterization and to understand, from the perspective of the knowledge system and the technological approaches of the firms, how the technological changes, recently applied to the Campos Basin, are implemented and what the origins of such changes are. As a secondary objective, this study has attempted to verify whether geographic agglomeration is a factor that favors innovation by the firms located there. Results have shown evidence of the existence of a group of firms in which geographical proximity has a positive influence on innovative activities.
\end{abstract}

Keywords: Clusters. Oil and gas. Innovation systems. Knowledge system. Technological changes. 
ALBU, M. Technological Learning and Innovation in Industrial Clusters in the South. Brighton: SPRU Electronic Working Paper $n^{\circ}$ 7, 1997.

AMATO NETO, J. Redes de cooperação produtiva e clusters regionais: oportunidades para as pequenas e médias empresas. São Paulo: Atlas, Fundação Vanzolini, 2000.

ATHREYE, S. Agglomeration and Growth: A Study of the Cambridge Hi-Tech Cluster. Standford: SIEPR Discussion Paper No. 00-42, 2001.

BALDWIN, J.; HANEL, P. Innovation and Knowledge Creation in an Open Economy: Canadian Industry and International Implications. Cambridge: Cambridge University Press, 2003.

BASANT, R. Knowledge Flows and Industrial Clusters - An Analytical Review of Literature. Ahmedabad: Indian Institute of Management, 2002.

BATISTA, R.; SWANN, P. Do firms in Clusters innovate more? Research Policy, Elsevier, v. 27, n. 5, p. 525-540, Sep. 1998.

BEAUDRY, C.; BRESCHI, S. Are firms in clusters really more innovative? Economics of Innovation and New Technologies, Taylor and Francis Journals, v. 12, n. 4, p. 325-342, Aug. 2003.

BELL, M.; ALBU, M. Knowledge Systems and Technological Dynamism in Industrial Clusters in Developing Countries. World Development, Elsevier, v. 27, n. 9, p. 1715-1734, Sep. 1999.

BELL, M.; PAVITT, K. The Development of Technological Capabilities. In: HAQUE, Irfan. Trade, Technology and International Competitiveness. Washington, D. C.: The World Bank, p. 69, 1995.

CARLSSON, B. (ed.) Technological Systems and Economic Performance: The Case of Factory Automation (Economics of Science, Technology and Innovation). Dordrecht: Kluwer Academic Publishers, 1995.

CARLSSON, B.; JACOBSSON, S. In search of a useful technology policy - general lessons and key issues for policy makers. In: CARLSSON, B, (ed.) Technological systems and Industrial Dynamics (Economics of Science, Technology and Innovation). Dordrecht: Kluwer Academic Publishers, 1997.

CARLSSON, B. et al. Innovation Systems: Analytical and Methodological Issues. Research Policy, Elsevier, v. 31, n. 2, p. 233-245, February, 2002.

CASAROTTO FILHO, N.; PIRES, L. H. Redes de pequenas e médias empresas e desenvolvimento local. São Paulo: Atlas, 1999.

CASSIOlato, J. E.; SZAPIRO, M. Arranjos e Sistemas Produtivos e Inovativos Locais no Brasil - Proposição de Políticas para a Promoção de Sistemas Produtivos Locais de Micro, Pequenas e Medias Empresas. In: Notas técnicas da fase II do Projeto "Proposição de políticas para a promoção de sistemas produtivos e inovativos locais de micro, pequenas e médias empresas brasileiras". Rio de Janeiro: UFRJ, Redesist, 2002.

EDQUIST, C. Systems of innovation approaches: Their emergence and characteristics. In EDQUIST, Charles. (Ed.) Systems of innovation - Technologies, institutions and organizations. London: Routledge, 1997.

FIGUEIREDO, P. Aprendizagem Tecnológica e Performance Competitiva. Rio de Janeiro: Ed. Fundação Getúlio Vargas., 2003.

FREEMAN, C. The national systems of innovation. In historical perspective. Cambridge Journal of Economics, v. 19, n. 1, p. 5-24, Feb. 1995.

GIULIANI, E. When the micro shapes the meso: learning and innovation in wine clusters. 2004, DPhil Thesis, SPRU, University of Sussex, Brighton.

LALL, S. Technological capabilities and industrialization. World Development, Elsevier, v. 20, n. 2, p. 165-186, Feb. 1992.

MALERBA, F. (ed.) Sectoral Systems of Innovation - Concepts, Issues and Analyses of Six Major Sectors in Europe. Cambridge: Cambridge University Press, 2004.

MALMBERG, A. Beyond the Cluster - Local Milieus and Global Connections. In: PECK, J.; YEUNG, W.-C. Y. (eds.) Remaking the Global Economy - Economic-Geographical Perspectives. Thousands Oaks: Sage Publications, 2003.

MALMBERG, A.; MASKELL, P. The elusive concept of localization economies Environment and Planning A, Pion, v. 34, n. 3, p. 429-449, 2002.

MARSHALL, A. Principles of Economics. London: Eight Edition, Macmillan, 1920.

NELSON, R.; NELSON, K. Technology, institutions, and innovation systems. Research Policy, Elsevier, v. 31, n. 2, p. 265-272, February, 2002.

PAVITT, K. Sectoral Patterns of Technical Change: Towards a Taxonomy and a Theory. Research Policy, Elsevier, v. 13, n. 6, p. 343-373, Dec. 1984.

PORTER, M. The Competitive Advantage of Nations. New York, Free Press, 1990.

Clusters and the New Economics of Competition. Boston: Harvard Business Review, November-December, 1998.

SCHMITZ, H.; NADVI, K. Clustering and Industrialization: Introduction. World Development, Elsevier, v. 27, n. 9, p. 1503-1514, September, 1999.

SILVA, R. C. R. S. A Indústria Petrolífera de Macaé: caracterização e potencialidades do Sistema Produtivo Local. 2004. Tese (Doutorado em Ciências da Engenharia), LEPROD - Laboratório de Engenharia de Produção, UENF, Campos dos Goytacazes - RJ.

SILVESTRE, B. S. Aglomeração Industrial de Petróleo e Gás da Região Produtora da Bacia de Campos: Conexões de Conhecimento e Posturas Tecnológicas das Firmas. 2006. Tese (Doutorado em Engenharia Industrial), DEI - Departamento de Engenharia Industrial, PUC-Rio, Rio de Janeiro.

YIN, R. Case Study Research: Design and Methods (Applied Social Research Methods). Thousands Oaks: Sage Publications, 2003. 


\section{APÊNDICE I}

As firmas incluídas na pesquisa de campo e suas características principais foram inseridas, de forma sintetizada, no Quadro a seguir.

\begin{tabular}{|c|c|c|c|c|c|}
\hline Empresa & Tipo & $\begin{array}{c}\text { Origem } \\
\text { de capital }\end{array}$ & $\begin{array}{l}\text { Áreas de } \\
\text { atuação }\end{array}$ & Funcionários & Observações \\
\hline Petrobrás & Operadora & Brasil & $\begin{array}{l}\text { E\&P de petróleo e gás; } \\
\text { transporte, refino e distribui- } \\
\text { ção de petróleo e derivados. }\end{array}$ & 54.000 no Brasil & $\begin{array}{l}\text { Iníciou as atividades de } \\
\text { exploração na Bacia de } \\
\text { Campos no início dos anos } \\
70\end{array}$ \\
\hline FMC Technologies & Equipamentos & EUA & $\begin{array}{l}\text { Sistemas submarinos; cabe- } \\
\text { ças de poço de superfície; } \\
\text { controle de fluidos; sistemas } \\
\text { flutuantes; outros. }\end{array}$ & 550 no Brasil & $\begin{array}{l}\text { Parceira da CBV (Compa- } \\
\text { nhia Brasileira de Válvulas) } \\
\text { desde } 1961 \text {, a qual comprou } \\
\text { em agosto de } 1998\end{array}$ \\
\hline Vetco Gray & Equipamentos & EUA & $\begin{array}{l}\text { Fornecimento de sistemas, } \\
\text { produtos e serviços em } \\
\text { atividades de perfuração e } \\
\text { produção de petróleo } \\
\text { onshore e offshore. }\end{array}$ & 230 no Brasil & $\begin{array}{l}\text { Antiga ABB, parceira da } \\
\text { Petrobras desde 1982, } \\
\text { comprada pela Vetco Gray } \\
\text { em } 1991\end{array}$ \\
\hline $\begin{array}{l}\text { Aker Kvaerner } \\
\text { Subsea }\end{array}$ & Equipamentos & Noruega & $\begin{array}{l}\text { Fornecimento de serviços } \\
\text { de construção e engenharia, } \\
\text { produtos em tecnologia e } \\
\text { soluções integradas para } \\
\text { indústrias; }\end{array}$ & 650 no Brasil & $\begin{array}{l}\text { O início das atividades no } \\
\text { Brasil datam de } 1975\end{array}$ \\
\hline Cooper Cameron & Equipamentos & EUA & $\begin{array}{l}\text { Fornecimento de sistemas } \\
\text { de controle de pressão e } \\
\text { direcionamento de fluxo; } \\
\text { sistemas para cabeça de } \\
\text { poço. }\end{array}$ & 230 no Brasil & $\begin{array}{l}\text { A mais recentes das forne- } \\
\text { cedoras de equipamentos } \\
\text { de poço, atuando no Brasil } \\
\text { desde } 1995\end{array}$ \\
\hline BJ Services & Serviços & EUA & $\begin{array}{l}\text { Serviços de bombeamen- } \\
\text { to/compressão; processos e } \\
\text { tubos, serviços de completa- } \\
\text { ção de poço; outros. }\end{array}$ & $\begin{array}{l}14.000 \text { em todo } \\
\text { mundo }\end{array}$ & $\begin{array}{l}\text { Informações não disponí- } \\
\text { veis }\end{array}$ \\
\hline Halliburton & Serviços & EUA & $\begin{array}{l}\text { Soluções digitais e consulto- } \\
\text { ria; serviços de perfuração; } \\
\text { avaliação de formação; siste- } \\
\text { mas de fluidos; outros. }\end{array}$ & 1.150 no Brasil & $\begin{array}{l}\text { Atua no Brasil em parceira } \\
\text { com a Petrobras desde } 1957\end{array}$ \\
\hline Schlumberger & Serviços & França & $\begin{array}{l}\text { Serviços de cimentação e } \\
\text { completação;serviços de } \\
\text { estimulação e testes de poço; } \\
\text { outros; }\end{array}$ & 1.280 no Brasil & $\begin{array}{l}\text { Presente no Brasil desde } \\
1946\end{array}$ \\
\hline Baker Huges & Serviços & EUA & $\begin{array}{l}\text { Perfuração e avaliação } \\
\text { de formação; serviços de } \\
\text { cimentação e completação } \\
\text { de poço; outro. }\end{array}$ & $\begin{array}{l}25.500 \text { em todo } \\
\text { mundo }\end{array}$ & $\begin{array}{l}\text { Informações não disponí- } \\
\text { veis }\end{array}$ \\
\hline Weatherford & Serviços & EUA & $\begin{array}{l}\text { Serviços de perfuração; } \\
\text { avaliação; completação; pro- } \\
\text { dução; intervenção; outros. }\end{array}$ & $\begin{array}{l}27.000 \text { em todo } \\
\text { mundo }\end{array}$ & $\begin{array}{l}\text { Informações não disponí- } \\
\text { veis }\end{array}$ \\
\hline
\end{tabular}

\section{APÊNDICE II}

Roteiro para pesquisa de campo

1. Questões com foco na identificação da empresa e do evento:

- Identificar o nome da empresa; e

- Identificar o evento (número). 
2. Questões com foco na determinação do evento:

- Determinar qual a última mudança tecnológica significativa implementada em seus produtos e processos; e

- Determinar quando ocorreu a última mudança tecnológica significativa implementada em seus produtos e processos (obs: situar no tempo).

3. Questões com foco na identificação da estrutura de conexões:

- Identificar as conexões de conhecimento que possibilitaram a implementação dessa mudança; e

- Se as conexões de conhecimento são extra-aglomerado, intra-aglomerado ou relativas a qual tipo de organização (obs: firma: fornecedor, consumidor, competidor, operador ou outros; ou não-firma: universidade, centro de pesquisa, órgão regulador, governo, agente de financiamento ou outros).

4. Questões com foco na determinação da postura das firmas frente à tecnologia:

- Determinar a intensidade das conexões de conhecimento que possibilitaram a implementação dessa mudança (obs: apenas aquisição de equipamentos, troca de informações, consultoria técnica especializada, P\&D conjunto ou outros);

- Determinar a intensidade do esforço do P\&D relativo a essa tecnologia (mudança tecnológica), se houver (obs: o esforço em P\&D nos mostra uma postura mais ativa em relação à aquisição da tecnologia - autonomia tecnológica); e

- Identificar a organização que a firma recorre, e se recorre, em caso de alteração na tecnologia em questão (obs: se a firma recorre a alguma organização é sinal que ela ainda é dependente em relação a essa tecnologia; se isso não acontece, percebemos que a busca de solução é intrínseca, o que mostra certa autonomia em relação à mesma).

\section{APÊNDICE III}

Os eventos tecnológicos discutidos no trabalho foram inseridos, de forma sintetizada, no Quadro a seguir.

\begin{tabular}{|c|c|c|}
\hline Evento & Descrição do evento & Ano \\
\hline 1 & Bombeio Centrífugo Submerso (BCS) acoplado à ANM & 2000 \\
\hline 2 & Blow Out Preventor (BOP) - equipamento de segurança de poço & Processo Contínuo \\
\hline 3 & Instalação da Base Adaptadora de Produção (BAP) enquanto perfura o poço & $2002 / 03$ \\
\hline 4 & Completion Riser $2.500 \mathrm{~m}$ & 2003 \\
\hline 5 & Completion Riser $3.000 \mathrm{~m}$ & 2006 \\
\hline 6 & Árvore de Natal Molhada Horizontal $3.000 \mathrm{~m}$ (ANMH) e acionamento horiz. de subconjuntos & 2003 \\
\hline 7 & Qualificação e certificação dos conectores e atuadores hidráulicos & 1999 \\
\hline 8 & Sistema de Controle Multiplexado (SCM) - controles eletrônicos & 2000 \\
\hline 9 & Sistema de Controle Acústico (SCA) - eliminação de umbilical & Futuro \\
\hline 10 & Horizontal Revestido Multi-Fraturado (HRMF) - estimulação de poço & 2005 \\
\hline 11 & Equalizer (não faz uso de bombeio e produz o poço como um todo) & Futuro \\
\hline 12 & Fraturamento de poços de forma horizontal (uniforme) & 2005 \\
\hline 13 & Navio Flextubo - operações submarinas sem depender de sondas de intervenção & Futuro (3 a 4 anos) \\
\hline 14 & Powering Up - coleta de dados de poço com ferramentas mais poderosas & 2004 \\
\hline 15 & Sistema de separação da água e do óleo - sistema de segurança ambiental & 1999 \\
\hline 16 & Fabricação própria de equipamentos no Brasil (instalação de fábrica) & 2005 \\
\hline 17 & Drill Pipe Riser (2.000 m) - instalação de ANM e Tubing Hanging & 1997 \\
\hline 18 & Controles eletrônicos para 3.000 (cabo ótico) & 2000 \\
\hline 19 & SURGIFRAL - sistema de estimulação por meio de 8 intervalos no poço & 2003 \\
\hline 20 & MERILAB - avaliação completa do poço por ressonância magnética & 2004 \\
\hline 21 & GEOTAP - equipamento que desce com a coluna para análise do poço enquanto perfura & 2004 \\
\hline 22 & Árvore de Natal Molhada Horizontal (ANMH) - intervenção através da árvore & $2000 / 01$ \\
\hline 23 & Instalação de BAP e das linhas de forma não simultânea compatível com a ANMH & $2000 / 01$ \\
\hline 24 & Melhoria nos Sistemas de Contenção de Areia & 1999 \\
\hline 25 & Sistema Seletivo de Produção - diversos intervalos no poço & 1999 \\
\hline
\end{tabular}




\section{Sobre os autores}

\section{Bruno dos Santos Silvestre}

Paulo Roberto Tavares Dalcol

Departamento de Engenharia Industrial - DEI, Pontifícia Universidade Católica do Rio de Janeiro - PUC-Rio,

Rua Marquês de São Vicente, 225, Gávea, CEP 22453-900, Rio de Janeiro, RJ, Brasil,

e-mails: bruss@ind.puc-rio.br; prtd@ind.puc-rio.br

Agradecimentos: Os autores agradecem à CAPES pelo apoio financeiro e aos revisores anônimos pelos comentários e sugestões dadas.

Recebido em 06/9/2006

Aceito em 04/5/2007 